Text: 3548

Abstract: 247

Tables: 6

\title{
Measuring Maladaptive Cognitions in Complicated Grief: Introducing the Typical Beliefs Questionnaire
}

Natalia A. Skritskaya, Ph.D., ${ }^{1}$ Christine Mauro, Ph.D., ${ }^{1}$ Matthew Olonoff, ${ }^{2}$ XinQiu, ${ }^{1}$ Sarah Duncan, ${ }^{3}$ Yuanjia Wang,

Ph.D., ${ }^{1}$ NaihuaDuan, Ph.D., ${ }^{1}$ Barry Lebowitz, Ph.D., ${ }^{4}$ Charles F. Reynolds III, M.D., ${ }^{5}$ Naomi M. Simon, M.D., M.Sc., ${ }^{6,7}$ Sidney Zisook, M.D., ${ }^{4} \&$ M. Katherine Shear, M.D. ${ }^{1}$

${ }^{1}$ Columbia University, New York, NY

${ }^{2}$ New York State Psychiatric Institute, New York, NY

${ }^{3}$ Fordham University, New York, NY

${ }^{4}$ University of California San Diego, San Diego, CA

${ }^{5}$ University of Pittsburgh Medical Center, Pittsburgh, PA

${ }^{6}$ Harvard Medical School, Boston, MA

${ }^{7}$ Massachusetts General Hospital, Boston, MA

Running Title:Measuring Maladaptive Cognitions

Key Words: Complicated Grief, Assessment, measurement/psychometrics,

Corresponding Author: Dr.Natalia Skritskaya, E-mail: ns2712@columbia.edu

Center for Complicated Grief, Columbia School of Social Work

1255 Amsterdam Ave, New York, NY 10027

\begin{abstract}
Objectives:Maladaptive cognitions related to loss are thought to contribute to development of complicated grief and are crucial to address in treatment, but tools available to assess them are limited. This paper introducesthe Typical Beliefs Questionnaire (TBQ), a 25-item self-report instrument to assess cognitions that interfere with adaptation to loss.
\end{abstract}

Design:Study participantscompleted an assessment battery during their initial evaluation and again after completing treatment at 20 weeks. Test-retest reliability was assessed on a subsample of the participants who did not show change in complicated grief severity after the first four weeks of treatment. To examine latent structure of the TBQ, an exploratory factor analysis (EFA) was performed.

Setting:Academic medical centersin Boston, New York, Pittsburgh and San Diego from 2010-2014. 
Participants:394 bereaved adults who met criteria for complicated grief.

Measurements:The TBQ along with assessments of complicated grief symptoms and related avoidance, depression symptoms, functional impairment, and perceived social support.

Results:The TBQ exhibited good internal consistency $(\alpha=.82)$ andtest-retest reliability ( $\mathrm{n}=105$; ICC $=.74)$. EFA indicated a five-factor structure:"Protesting the Death,” "Negative Thoughts About the World,” "Needing the Person,” "Less Grief is Wrong” and "Grieving Too Much.”The total score and all factors showed sensitivity to change with treatment.

Conclusions:This new tool allows a clinician to quickly and reliably ascertain presence of specific maladaptive cognitions related to complicated grief, and subsequently, to use the information to aid a diagnostic assessment, to structure the treatment, and to measure treatment outcomes. 


\section{Introduction}

Losing a loved one is one of the most painful experiences a person faces, yet it is also very common.

Over 2.5 million people in the United States die each year, leaving millions bereaved(1, 2).Among those, about 7\% (3)experience grief complications that impede the adjustment process. The resulting syndrome of Complicated Grief (CG) includes symptoms of prolonged acute grief and complicating thoughts and behaviors, including persistent suicidal ideation(2).CG is associated with impairment in functioning $(4,5)$ and an increased risk of health problems(5), such as cancer and cardiovascular issues(6), and overallincreased mortality.

For the majority of bereaved people, acute intense grief evolves over time into an integrated form, where painful emotions become muted and theperson accepts the finality of the loss and is able to envision his or her future with possibilities for joy and satisfaction(2).This transformation does not happen in complicated griefbecause the natural adaptive process hasbecome blocked.Maladaptive cognitions are thought to play a central roleinthe development and maintenance of complicated grief(2, 7).Negative cognitionshave been shown to correlate with concurrent and prospective symptoms of CG(8).Additionally,ruminations(9) and certain types of thoughts, such as self-blame,are predictive of difficulties in long-term recovery in bereavement(10), while changes in thinking patterns are related to better physical and psychological outcomes(11).

Considering the chronic course of untreated CG(7)andthe distress and impairment it causes, treatment is of high importance. To address this need Complicated Grief Treatment (CGT), a short-term targeted psychotherapy,was developed and testedin three large clinical trials, which all supported itseffectiveness(1214).In working to develop this treatment we observed that patterns of ruminative thoughts often included counter-factual thoughts about the circumstances of the death, e.g. thinking that someone could have prevented the death, worries about forgetting the loved one,or concernsabout the intensity of grief. We hypothesized that, along with avoidance behavior and difficulty modulating emotional activation, maladaptive thinking could complicate grief and impede adaptation to the loss. The goal of the treatment we developed is to identify and 
resolve complicating thoughts and behaviors and to facilitate the natural adaptation to loss $(12,15)$.Therefore,we thought it would be useful tofurther explore the role of problematic cognitions during complicated grief treatment.

These maladaptive cognitions do not seem to besufficiently captured by existing measures of complicated grief symptoms. The Inventory of Complicated Grief (ICG)(16) or the Structured Clinical Interview for Complicated Grief (SCI-CG)(17)haveeach a couple of items that measure grief-related maladaptive cognitions (e.g., thoughts related to anger or self-blame), but neither does it comprehensively. The cognitions are also different from grief-related avoidance and are not captured by the Grief-related Avoidance Questionnaire (GRAQ)(18). To address this gap, the Typical Beliefs Questionnaire (TBQ) ${ }^{1}$ was created and includes 25 typical maladaptive cognitions we have often observed among help-seeking patients with CG.The items were developed by consensus discussions in our clinical research team and revised based on feedback from patients and assessors.

The purposeof thispaper is to describethe performance characteristics of the TBQ,including reliability and validity, factor structure and sensitivity to change in order to support its potential utility in clinical care and research. We hypothesizethat this instrument has good psychometric properties and that it can be a useful tool for directing attention to problematic thinking in CG patients.

\section{MATERIALS AND METHODS}

\section{Sample}

Participants were 394treatment-seeking bereaved adults (mean age =53.0, SD=14.6; 78\%females) evaluated as part of an NIMH-sponsored multicenter(Massachusetts General Hospital, Columbia University, University of California - San Diego, and University of Pittsburgh Medical Center) clinical trial examining the

\footnotetext{
${ }^{1}$ The full TBQ scale can be obtained through the Center for Complicated Grief at Columbia University at www.complicatedgrief.columbia.edu.
} 
efficacy of citalopram and CGT(12) for treating CG. The participants were recruited through radio ads, internet media, and clinician referrals from March2010 until September 2014. The study protocol was approved by the respective Institutional Review Boards at each site, and all participants provided written informed consent.

Participants scored $\geq 30$ on the ICG(16) and were confirmed by the study PI or his or her delegate to have CG on clinical interview, establishing prolonged acute grief symptoms accompanied by complicating dysfunctional thoughts, feelings or behaviors. Individuals were excluded from the study if they had substance abuse or dependence within the past 6 months, history of a psychotic or bipolar I disorder, current psychotherapy or treatment with an antidepressant, a Montreal Cognitive Assessment (MoCA)(19) score below 21, active homicidal or serious suicidal ideation. Eligible participants were randomized to receive up to 20 weeks of citalopram or placebo either with supportive clinical management or with CGT. Treatment response was defined as a rating by an independent evaluator of $1=$ very much improved or $2=$ much improved on a grief-anchored Clinical Global Impression-Improvement Scale(20).

\section{Study Assessments}

The TBQ is a 25-item self-report designed to measure maladaptive thinkingin individuals with complicated grief. The instrument asks individuals to rate their agreement with statements like "You should have done something to prevent the death or make it easier," and "Life is unbearable without [the loved one who died]," on a 5-point scale from 0 (not at all) to 4 (very strongly). A total score ranging from 0 to 100 is calculated by summingall items. A more clinically relevantalternative scoring approach can be used, by selecting only items endorsed as "strongly" or "very strongly" (a score of 3 or 4). Items endorsed at these high levels are more likely to be clinically meaningful and may be useful to track during treatment or as a target of intervention.

To establish convergent validity,measures ofCG symptoms -the 19-item self-report ICG(16) $($ Cronbach'salpha $=0.75)$ and the 31-item SCI-CG(17)(Cronbach's alpha of 0.76),were used. 
Discriminant validitywas examined withthe 16-item Quick Inventory of Depressive Symptomatology - SelfReport $($ QIDS-SR 16$)(21)($ Cronbach's alpha $=0.86)$, the 19-item clinician-administered Structured Interview Guide for the Hamilton Anxiety rating scale (SIGH-A)(22) (Cronbach's alpha = 0.80), the16-item self-report Interpersonal Support Evaluation List(ISEL- Short Form) (23, 24)(Cronbach’s alpha= 0.83), and the 15-item self-reportGRAQ(18)(Cronbach's alpha = 0.87).The 5-item Work and Social Adjustment Scale (WSAS) (25) was used to asses functional impairment and adapted tospecifically assess impairment related to the loss of a loved one (Cronbach’s alpha= 0.81).

\section{Statistical analyses}

Descriptive statistics were used to summarize the demographics of the study sample. Continuous variables were summarized with means and standard deviations andcategorical variables with counts and frequencies. In addition to examining the mean and SD of the total score,frequency distributions of individual items wereexamined.To compare samples, t-tests were used for the continuous variables and chi-squared tests for the categorical variables.

TBQ total score is calculated by summing all items. We further created a dichotomized score (26, 27),in which endorsement on each item was coded as present (strongly or very strongly) or absent (not at all, somewhat or moderately), in order to achieve a more clinically meaningful method of scoring. We have retained only dichotomous scoring for all analyses.For analyses below, items on the ICG and GRAQ were also dichotomized as present (often or always) or absent (not at all, rarely or sometimes).

To investigate factor structure of the TBQ, an exploratory factor analysis (EFA) of dichotomous variables was performed using robust weighted least squares (WLSMV in Mplus 6.0)(28) and geomin oblique rotation. A common way to estimate factor loadings for an EFA, when data is normally distributed, is by maximum likelihood estimation. When the data are not normally distributed, as is the case with dichotomous or ordinal items such as ours, maximum likelihood techniques may lead to bias (29). In this case, WLSMV was 
shown to be a more appropriate option $(29,30)$. Model adequacy was assessed using the chi-square goodnessof-fit test, CFI, and RMSEA and also based on interpretability of the factors. Interpretation of the factor analysis results was guided by examining factor loadings. Items with a dominant loading (larger than .35) on just one factor were interpreted to be indicative of that factor. In instances where an item had multiple loadings larger than .35, or no large loadings at all, content interpretation was used to guide placement of that item (31).

In addition to the EFA, to test the uni-dimensionality of the overall set of items in the presence of multiple factors and to support the use of a TBQ total score, a bifactor model was fit to the data(32). This model specified one factor that included all TBQ items and then additional factors to incorporate the structure of the subscales identified by the EFA. Adequacy of the model was assessed using fit statistics (RMSEA of .08 or lower(33), CFI and TLI of .90 or higher $(34,35))$. Further, support for the uni-dimensionality of the scale was determined by statistically significant factor loadings on the overall factor.

Internal consistency was assessed by Cronbach's alpha on all of the scale items as well as for each subset of items that comprise the factors identified in the EFA.. Test-retest reliability was evaluatedusingintraclass correlation coefficients (ICC) for week 1 and week 4 scores on a sub-sample of 105 study participants who had no change on CG-anchored Clinical Global Impression -Improvement Scale (CG-CGI-I)(20) at week 4.To assess convergent and discriminant validity, baseline TBQ scores were compared, using Pearson's correlation coefficients, to several other measures administered at the same visit. Effect of demographic variables on the TBQ total score was examined using linear regression. A two-sided $p$-value less than alpha $=0.05$ was considered statistically significant in all cases. These analyses were carried out using SAS 9.4.

To examine sensitivity of the TBQ to change with treatment,we have compared change in TBQ scores from baseline to week 20 in treatment responders and non-responders both forthe total score and by factor. To estimate effect size within each group (responders and non-responders), Cohen’s d was computed(36) as the mean difference of pre- and post-treatment score divided by the standard deviation of the difference. 


\section{RESULTS}

\section{Descriptive Statistics}

Table 1 presents basic descriptive statistics of the sample. The mean total TBQ score was 54.14(SD = 16.99), while the mean total score of dichotomized items ( 0 s and $1 \mathrm{~s})$ was $11.84(\mathrm{SD}=5.22)$. These results suggestthat on average about half of the TBQ items were endorsed as "strongly” or "very strongly” present. We used dichotomized scoring for all the analyses reported below because we consider this to be more clinically meaningful and interpretable.

Across all 25 items, the rate of positive endorsement on dichotomized responses (see Table 2) ranged from 9.8\% for item 11 (“Grieving less would mean you are uncaring, heartless or cold”) to 80.7\% for item 6 (“It isn't fair that this person died”), with a mean positive endorsement rate of $47.3 \%$.

Age was a significant predictor of the TBQ total score, with older participants endorsing lower scores. Similarly,retired participants had lower TBQ scores as compared to employed and unemployed participants $(\mathrm{M}=10.07$ vs. $\mathrm{M}=11.88$ and $\mathrm{M}=13.26$, respectively; $F(2,391)=7.66, p=0.001)$, although a difference of less than two points on the dichotomized scale might not be clinically meaningful.African-American participants scored significantly higher on the TBQ as compared to participants of White and other races (M=14.12 vs. $\mathrm{M}=11.65$ and $\mathrm{M}=10.87$ respectively; $F(2,391)=4.57, p=0.011$;mean differences 2.47 (95\% CI: $0.41-4.54)$ and 3.26 (95\% CI: $0.33-6.19)$ ). Participants with education of high school or less had higher TBQ scores as compared to those with some college or completed college degree (M=14.43 vs. $M=11.73$ and $\mathrm{M}=11.37$,respectively; $F(2,391)=6.49, p=0.002$;mean differences2.71 (95\% CI: $0.61-4.80)$ and 3.06 (95\% CI: 1.05 - 5.07)). There was no difference in total baseline TBQ scores by gender, Hispanic ethnicity, marital status, cause of death, including suicide, or relationship to the deceased.

\section{Factor Structure}


All 25 TBQ items were entered into the exploratory factor analysis. Factor analyses revealed that the first six eigenvalues were greater than $1(8.04,2.86,2.19,1.75,1.40,1.34)$, suggesting that multiple factors explain much of the variability. The one-factor model explained 32.2\% of variance while the four-, five- and six-factor models explained 59.4, 65.0 and 70.3\% of the variance respectively. The goodness of fit statistics for the five-factor model indicated a very good fit at CFI $=.977, \mathrm{RMSEA}=.033, \chi^{2}=264.37$ on $d f=185$ with $p=$ 0.0001, but were also good for the four- and six-factor models. After examining the specific items and factor loadings for these models, the five-factor model appeared to provide the best interpretable fit. The TBQ items, respective factor loadings and variance explained by each of the factors for the five-factor model are presented in Table 3. Item clusters in the model were formed based almost entirely on empirically driven results motivated by clearly large loadings relating items to factors. Items 1, 2, and 6 had loadings of .35 or larger on two factors and ultimately were placed on a factor where they loaded the strongest. Two items did not load on any of the factors and were not included in the factor structure. The first factor was labeled “1-Protesting the Death,” while subsequent factors were labeled “2-Negative Thoughts About the World,” “3-Needing the Person,” “4-Less Grief is Wrong” and “5-Grieving Too Much.” Correlations among the factors varied. The strongest correlation (.52) was between factor 3 and factor 4and the weakest (.04) between factor 1 and factor 5 (Table 4).

Factor scores were further examined for the subgroups that showed differences in total TBQ scores. The analyses revealed that as participants' age increases, scores on factors 1 (“Protesting the Death”) and 4 (“Less Grief is Wrong”) decrease. African-Americans scored higher on factor 1 than White participants. Respondents with high school or less education scored higher than people who attended some college or completed college on factors 3 (“Needing the Person”) and 4.

The bifactor model, which included a single factor with all TBQ items, as well as five additional factors informed by the EFA, had adequate fit (RMSEA=0.042, CFI=0.95, TLI=0.94). All TBQ item factor loadings were statistically significant, supporting the use of aTBQ total score in addition to factor scores. 


\section{Reliability}

The TBQ demonstrated good internal consistency. The Cronbach's alpha coefficient for the overall sample was 0.83 . Cronbach’s alpha coefficients for individual factors ranged from .79 to .59 and are reported in Table 4. Test-retest reliability was good with ICC $=0.70$.

\section{Convergent and Discriminant Validity}

Evidence of convergent and discriminant validity was provided by correlations of the TBQ with other measures of complicated grief symptoms, grief-related avoidance, depression, anxiety, functional impairment and perceived social support (Table 5). As expected, the TBQ total scores were significantly and moderately correlated with measures of complicated grief symptoms, the ICG and the SCI-CG (Table 5).This suggests that, while constructs measured by the TBQ and the ICG with SCI-CG overlap significantly, the TBQ captures additional information. The TBQ was also moderately correlated with a measure of functional impairment, the WSAS, a measure of grief-related avoidance, the GRAQ, and a measure of depression, the QIDS-SR, while correlation with ameasure of anxiety, the SIGH-A,wassomewhat lower(Table 5).The TBQ was mildly correlated with all subscales of a measure of perceived social support, the Interpersonal Support Evaluation List(ISEL)with the lowest correlationfor the Tangible Support subscale andthe highestfor Self Esteem.

\section{Sensitivity to Change with Treatment}

There is a statistically and clinically significant change from pre- to post-treatment in TBQ total scores among treatment responders. This change was not seen in non-responders(Table 6).Average number of TBQ items endorsed at a level of 3 or 4 (strongly or very strongly agree) decreased from 11 to 3 among responders and 13 to 11 among non-responders.Similar pattern of significant change in scores from pre- to post-treatment was observed in responders for each of the TBQ factors.

\section{DISCUSSION}


Initial evidenceshowed the TBQ to be a valid and reliable instrument for measuring maladaptive cognitions in patients with complicated grief.The TBQ demonstrated good internal consistency and acceptable test-retest reliability. In support ofconstruct validity, the TBQ strongly to moderately correlated with self-report and interview measures of complicated grief symptoms, the ICG and SCI-CG, and with the measure of griefrelated avoidance. At the same time, the TBQ had low correlations with the measure of perceived social support, and moderate to low correlations with measures of depression, anxiety and functional impairment, providing evidence of discriminant validity. These correlations supportusefulness of the TBQ in uniquely capturing maladaptive cognitions, a grief complication and one of key features of CG. Thus, the TBQ may help to discriminate the condition of complicated grief in practice and focus of treatment.

Five distinct and clinically meaningful TBQ item clusters emerged as a result of the exploratory factor analysis. The first factor includes thoughts that a loved one should not have died, that the death was not fair or was preventable. This factor explained the largest portion of variance in TBQ scores, and 3 of the 5 items in this subscale were endorsed by more than $70 \%$ of the sample. These findings are consistent with the observation that ruminations about circumstances of the death and difficulty accepting the loss are among the defining symptoms of complicated grief $(37,38)$. The second factor focuses on negative thoughts about the world such as bad things are uncontrollable and the world is not safe. This theme parallels maladaptive cognitions that are thought to underlie post-traumatic psychopathology in PTSD(39). The third factor reflects thoughts of needing the deceased person and thinking that the only thing that can help is to have them back. The fourth cluster reflects beliefsthat grieving less is wrong. People with complicated grief often feel that grief is their main tie to the deceased, and that grieving less would mean they did not really love the deceased. By contrast, thefifth cluster highlights an awareness bythe bereaved person that they are grieving too much and that they do not understand why grief is not getting better. All factors were sensitive to change with treatment, which emphasizes the clinical importance of these categories of maladaptive thoughts. 
This instrument identifies typical counterfactual thoughts characteristic of complicated grief. For example, three of the TBQ items were endorsed by more than $75 \%$ of the sample. Two of the items involved counterfactual thoughts that the loved one did not have to die or did not have to die in that way.These thoughts are indicative of resistance of acceptance of reality and are clinically very typical of complicated grief. Similarly, the third item, the idea that grieving less would be in some way unfair to their loved one is also very common among people with complicated grief and deserves clinical attention as it might interfere with treatment.

Another clinical application of the TBQ that deserves mention is its ability to discriminate between different circumstances of the death. Previous studies reported thatthose who lost a child showed a different pattern of endorsement on the TBQ compared to other losses. For example, people with CG after child loss were three times more likely to endorse item 2: "I should have done something to prevent/ease death"(40). Those who lost a loved one to suicideendorsed different items than those whose loved one died in another violent manner and from those whose death was non-violent. (Zisook et al., unpublished data).

In our clinical trials of CGT the TBQ is administered before session 1 to help a clinician identify and target specific maladaptive thoughts. The information is used to inform case formulation and to guide the clinician in addressing grief complications.The TBQ is re-administered mid-treatment to gauge progress and to inform the second part of treatment.

This study is limited by the inclusion of only participants who were treatment-seeking and all were identified as having complicated grief. Results may not be generalizable to other clinical samples or to nonclinical populations. However, we consider the primary use of this instrument to be for individuals seeking treatment for complicated grief. Our study showed some evidence of demographic differences,butthe sample was limited in its ability to examine these differences. In addition, even though the TBQ is intended for use with clinical population, it might be informative to administer the instrument to broader samples of bereaved people 
without CG to further characterize the performance of the instrument and to understand what might contribute to high scores on the TBQ. Another limitation is that we did not compare the TBQ performance to another measure of maladaptive cognitions in grief, for example, the Grief Cognitions Questionnaire(41, 42).

\section{CONCLUSIONS}

TheTBQ is a psychometrically soundmeasure that identifies typical counterfactual thoughts characteristic of complicated grief. This scale can help focus complicated grief treatment and it is sensitive to meaningful clinical change. Additionally, the TBQ might be useful in further understanding patterns of endorsement of specific cognitions that may vary within individuals and across death related-factors such as the circumstances of the loss. This scale assesses an aspect of CG that is prevalent and clinically significant, as such it is a promising assessment tool for use in clinical and research settings.

\section{AKNOWLEDGMENTS}

The study was supported by grants from theNational Institute of Mental Health: R01MH060783 awarded to Dr. Shear, R01MH085297 awarded to Dr. Zisook, R01MH085308 awarded to Dr. Simon, and R01MH085288 awarded to Dr. Reynolds; and from the American Foundation for Suicide Prevention (LSRG-S-172-12). 


\section{REFERENCES}

1. Antonucci TC, Akiyama H,Takahashi K: Attachment and close relationships across the life span. Attachment \& human development 2004; 6:353-370

2. Shear MK: Grief and mourning gone awry: pathway and course of complicated grief. Dialogues in clinical neuroscience 2012; 14:119-128

3. Kersting A, Brahler E, Glaesmer $\mathrm{H}$, et al: Prevalence of complicated grief in a representative populationbased sample. Journal of affective disorders 2011; 131:339-343

4. Simon NM, Shear KM, Thompson EH, et al: The prevalence and correlates of psychiatric comorbidity in individuals with complicated grief. Compr Psychiatry 2007; 48:395-399

5. $\quad$ Lannen PK, Wolfe J, Prigerson HG, et al: Unresolved grief in a national sample of bereaved parents: impaired mental and physical health 4 to 9 years later. Journal of Clinical Oncology 2008; 26:5870-5876

6. Prigerson HG, Bierhals AJ, Kasl SV, et al: Traumatic grief as a risk factor for mental and physical morbidity. American Journal of Psychiatry 1997; 154:616-623

7. Shear MK: Clinical practice. Complicated grief. The New England journal of medicine 2015; 372:153160

8. Boelen PA, van den Bout J,van den Hout MA: Negative cognitions and avoidance in emotional problems after bereavement: a prospective study. Behaviour research and therapy 2006; 44:1657-1672

9. $\quad$ Nolen-Hoeksema S, McBride A,Larson J: Rumination and psychological distress among bereaved partners. Journal of personality and social psychology 1997; 72:855

10. Field NP,Bonanno GA: The role of blame in adaptation in the first 5 years following the death of a spouse. Am Behav Sci 2001; 44:764-781

11. Pennebaker JW, Mayne TJ,Francis ME: Linguistic predictors of adaptive bereavement. Journal of personality and social psychology 1997; 72:863

12. Shear K, Frank E, Houck PR, et al: Treatment of complicated grief: a randomized controlled trial. JAMA 2005; 293:2601-2608

13. Shear MK, Wang Y, Skritskaya N, et al: Treatment of complicated grief in elderly persons: a randomized clinical trial. JAMA psychiatry 2014; 71:1287-1295

14. Shear M, Reynolds CF, Iii, et al: Optimizing treatment of complicated grief: A randomized clinical trial. JAMA psychiatry 2016; 73:685-694

15. Shear MK: Getting straight about grief. Depression and anxiety 2012; 29:461-464

16. Prigerson HG, Maciejewski PK, Reynolds CF, 3rd, et al: Inventory of Complicated Grief: a scale to measure maladaptive symptoms of loss. Psychiatry research 1995; 59:65-79

17. Bui E, Mauro C, Robinaugh DJ, et al: The Structured Clinical Interview for Complicated Grief: Reliability, Validity, and Exploratory Factor Analysis. Depression and anxiety 2015;

18. Shear K, Monk T, Houck P, et al: An attachment-based model of complicated grief including the role of avoidance. European archives of psychiatry and clinical neuroscience 2007; 257:453-461

19. Nasreddine ZS, Phillips NA, Bedirian V, et al: The Montreal Cognitive Assessment, MoCA: a brief screening tool for mild cognitive impairment. Journal of the American Geriatrics Society 2005; 53:695-699 20. Shear MK, Reynolds CF, Simon N, et al: Optimizing Treatment of Complicated Grief: A Multicenter Randomized Clinical Trial. JAMA psychiatry 2016;

21. Rush AJ, Trivedi MH, Ibrahim HM, et al: The 16-Item Quick Inventory of Depressive Symptomatology (QIDS), clinician rating (QIDS-C), and self-report (QIDS-SR): a psychometric evaluation in patients with chronic major depression. Biological psychiatry 2003; 54:573-583 
22. Shear MK, Vander Bilt J, Rucci P, et al: Reliability and validity of a structured interview guide for the Hamilton Anxiety Rating Scale (SIGH-A). Depression and anxiety 2001; 13:166-178

23. Cohen S,Hoberman HM: Positive events and social supports as buffers of life change stress. Journal of applied social psychology 1983; 13:99-125

24. Payne TJ, Andrew M, Butler KR, et al: Psychometric Evaluation of the Interpersonal Support Evaluation List-Short Form in the ARIC Study Cohort. SAGE Open 2012; 2:2158244012461923

25. Mundt JC, Marks IM, Shear MK, et al: The Work and Social Adjustment Scale: a simple measure of impairment in functioning. The British journal of psychiatry : the journal of mental science 2002; 180:461-464

26. Simon NM, Wall MM, Keshaviah A, et al: Informing the symptom profile of complicated grief. Depression and anxiety 2011; 28:118-126

27. Prigerson HG, Shear MK, Jacobs SC, et al: Consensus criteria for traumatic grief. A preliminary empirical test. The British journal of psychiatry : the journal of mental science 1999; 174:67-73

28. Muthén LK,Muthén BO: Mplus User's Guide, Los Angeles, CA, Muthén \& Muthén, 1998-2010

29. Beauducel A,Herzberg PY: On the Performance of Maximum Likelihood Versus Means and Variance Adjusted Weighted Least Squares Estimation in CFA. Structural Equation Modeling: A Multidisciplinary Journal 2006; 13:186-203

30. Li CH: Confirmatory factor analysis with ordinal data: Comparing robust maximum likelihood and diagonally weighted least squares. Behavior research methods 2015;

31. Nunnally JC,Bernstein IH: Psychometric theory, McGraw-Hill, 1994

32. Reise SP, Morizot J,Hays RD: The role of the bifactor model in resolving dimensionality issues in health outcomes measures. Quality of life research : an international journal of quality of life aspects of treatment, care and rehabilitation 2007; 16 Suppl 1:19-31

33. Browne MW,Cudeck R: Alternative Ways of Assessing Model Fit. Sociological Methods \& Research 1992; 21:230-258

34. Bentler PM: Comparative fit indexes in structural models. Psychol Bull 1990; 107:238-246

35. Kline RB: Principles and Practice of Structural Equation Modeling, 2nd. New York, Guilford Press, 2005

36. Cohen J: Statistical power analysis for the behavioral sciences, New York: Academic Press, 1988

37. Prigerson HG, Horowitz MJ, Jacobs SC, et al: Prolonged grief disorder: Psychometric validation of criteria proposed for DSM-V and ICD-11. PLoS medicine 2009; 6:e1000121

38. Shear MK, Simon N, Wall M, et al: Complicated grief and related bereavement issues for DSM-5. Depression and anxiety 2011; 28:103-117

39. Foa EB, Ehlers A, Clark DM, et al: The Posttraumatic Cognitions Inventory (PTCI): Development and validation. Psychological assessment 1999; 11:303

40. Zetumer S, Young I, Shear MK, et al: The impact of losing a child on the clinical presentation of complicated grief. Journal of affective disorders 2015; 170:15-21

41. Boelen PA,Lensvelt-Mulders GJLM: Psychometric properties of the Grief Cognitions Questionnaire (GCQ). J Psychopathol Behav 2005; 27:291-303

42. Boelen PA, van den Bout J,van den Hout MA: The role of cognitive variables in psychological functioning after the death of a first degree relative. Behaviour research and therapy 2003; 41:1123-1136 
Table 1. Demographic characteristics of the overall sample $(n=394)$.

\begin{tabular}{|c|c|}
\hline Demographic characteristics & M (SD) \\
\hline Age (years) & $53.0(14.6)$ \\
\hline \multirow{2}{*}{ Time since the loss (years) } & $4.7(7.2)$ \\
\hline & $\mathbf{N}(\%)$ \\
\hline \multicolumn{2}{|l|}{ Race } \\
\hline Black or African American & $39(10 \%)$ \\
\hline White & $324(82 \%)$ \\
\hline Unknown or Other & $31(8 \%)$ \\
\hline \multicolumn{2}{|l|}{ Gender } \\
\hline Male & $86(22 \%)$ \\
\hline Female & $308(78 \%)$ \\
\hline \multicolumn{2}{|l|}{ Ethnicity } \\
\hline Hispanic or Latino Origin & $45(11 \%)$ \\
\hline Not Hispanic or Latino Origin & $349(89 \%)$ \\
\hline \multicolumn{2}{|l|}{ Education } \\
\hline High School or Less & $44(11 \%)$ \\
\hline Some College & $139(35 \%)$ \\
\hline College Degree or Higher & $211(54 \%)$ \\
\hline \multicolumn{2}{|l|}{ Marital Status } \\
\hline Never Married & 97 (25\%) \\
\hline Married & $92(23 \%)$ \\
\hline Divorced or Separated & $68(17 \%)$ \\
\hline Widowed & $137(35 \%)$ \\
\hline \multicolumn{2}{|l|}{ Employment } \\
\hline Employed or Homemaker & $235(60 \%)$ \\
\hline Retired & $74(19 \%)$ \\
\hline Unemployed & $85(22 \%)$ \\
\hline \multicolumn{2}{|c|}{ Deceased Relationship to the participant } \\
\hline Parent & 113 (29\%) \\
\hline Child & $80(20 \%)$ \\
\hline Spouse/Partner & $143(36 \%)$ \\
\hline Other & $58(15 \%)$ \\
\hline \multicolumn{2}{|l|}{ Cause of Death } \\
\hline Illness less than 1 month & 79 (20\%) \\
\hline Illness greater than 1 month & $175(44 \%)$ \\
\hline Accident & $58(15 \%)$ \\
\hline Murder & $16(4 \%)$ \\
\hline Suicide & $58(15 \%)$ \\
\hline Other & $8(2 \%)$ \\
\hline
\end{tabular}


Table 2. Rates of positive endorsement on dichotomizedTBQ items ( $N=394)$.

\begin{tabular}{rlc}
\hline & TBQ Item & $\begin{array}{c}\text { Endorsement } \\
\text { \% }\end{array}$ \\
\hline 1 & Death shouldn't have happened & $77.7 \%$ \\
2 & Done something to prevent/make easier & $55.6 \%$ \\
3 & Someone else could done something to prevent/make easier & $52.5 \%$ \\
4 & Bad things are uncontrollable & $71.1 \%$ \\
5 & Grief main tie to loved one & $39.6 \%$ \\
6 & It isn't fair that this person died & $80.7 \%$ \\
7 & Should have expressed your love more & $50.3 \%$ \\
8 & No space that is safe anymore & $26.1 \%$ \\
9 & Don't understand why grief is not getting better & $63.5 \%$ \\
10 & World filled with unpredictable dangers & $47.7 \%$ \\
11 & Grieving less would mean you are uncaring, heartless or cold & $19.8 \%$ \\
12 & Your loved one did not have to die in this way & $76.1 \%$ \\
13 & Life is unbearable without the person who died & $43.4 \%$ \\
14 & The only thing that can really help you is to have this person back & $32.7 \%$ \\
15 & You need a confidant, someone who you could talk to and feel close to & $54.6 \%$ \\
16 & Other people are tired of your endless grief & $28.2 \%$ \\
17 & Loved one should have taken better care of her or himself & $36.0 \%$ \\
18 & Need the person who died to help you cope with stress or problems & $35.3 \%$ \\
19 & You have nowhere to turn now that your loved one is gone & $27.9 \%$ \\
20 & Need to guard against forgetting the person who died & $22.3 \%$ \\
21 & Need to stop grieving so much & $48.7 \%$ \\
22 & Something is wrong with you because you are grieving so much \\
23 & Spending time with other people is hard because can't share grief & $38.1 \%$ \\
24 & You can't stop wishing your loved one was still here & $38.3 \%$ \\
25 & You need this person so much that they should not have died & $71.1 \%$ \\
\hline & & $46.5 \%$ \\
\hline
\end{tabular}


TABLE 3. Factor loadings for the five-factor model.

\begin{tabular}{|c|c|c|c|c|c|c|}
\hline & \multirow[t]{2}{*}{ TBQ Item } & \multicolumn{5}{|c|}{ Factors } \\
\hline & & 1 & 2 & 3 & 4 & 5 \\
\hline 12 & Your loved one did not have to die in this way & 0.78 & 0.00 & 0.15 & 0.30 & -0.04 \\
\hline 1 & Death shouldn't have happened & 0.75 & 0.05 & 0.49 & -0.15 & 0.03 \\
\hline 6 & It isn't fair that this person died & 0.69 & 0 & 0.40 & -0.00 & 0.03 \\
\hline 3 & Someone else could done something to prevent/make easier & 0.65 & 0.05 & -0.03 & 0.28 & -0.01 \\
\hline 2 & Done something to prevent/make easier & 0.58 & -0.10 & -0.01 & 0.54 & 0.02 \\
\hline 4 & Bad things are uncontrollable & 0.18 & 0.79 & -0.03 & -0.05 & -0.07 \\
\hline 10 & World filled with unpredictable dangers & -0.04 & 0.73 & -0.01 & 0.06 & 0.11 \\
\hline 8 & No space that is safe anymore & 0.03 & 0.59 & 0.17 & 0.25 & 0 \\
\hline 14 & The only thing that can really help you is to have & 0.03 & -0.08 & 0.95 & 0.07 & -0.24 \\
\hline 13 & Life is unbearable without the person who died & -0.03 & 0.03 & 0.81 & 0.02 & -0.13 \\
\hline 24 & You can’t stop wishing your loved one was still here & 0.09 & -0.04 & 0.80 & 0.08 & -0.02 \\
\hline 25 & You need this person so much that they should not have died & 0.13 & 0.00 & 0.78 & -0.01 & 0.03 \\
\hline 18 & Need the person who died to help you cope with stress or problems & -0.32 & 0.01 & 0.75 & -0.06 & 0.11 \\
\hline 19 & You have nowhere to turn now that your loved one is gone & -0.30 & 0.13 & 0.64 & 0.06 & 0.17 \\
\hline 11 & Grieving less would mean you are uncaring, heartless or cold & -0.07 & 0.07 & 0.05 & 0.75 & -0.04 \\
\hline 20 & Need to guard against forgetting the person who died & 0.00 & -0.06 & 0.08 & 0.73 & 0.00 \\
\hline 7 & Should have expressed your love more & 0.30 & 0.09 & -0.15 & 0.56 & 0.06 \\
\hline 23 & Spending time with other people is hard because can't share grief & -0.05 & 0.00 & 0.10 & 0.44 & 0.34 \\
\hline 5 & Grief main tie to loved one & 0.04 & 0.09 & 0.23 & 0.36 & 0.04 \\
\hline 22 & Something is wrong with you because you are grieving so much & 0.05 & -0.07 & -0.16 & 0.03 & 1.01 \\
\hline 21 & Need to stop grieving so much & 0.06 & -0.03 & 0.03 & -0.07 & 0.80 \\
\hline 9 & Don't understand why grief is not getting better & -0.08 & 0.14 & 0.14 & 0.01 & 0.64 \\
\hline 16 & Other people are tired of your endless grief & 0.00 & 0.14 & 0.17 & 0.19 & 0.39 \\
\hline 15 & You need a confidant, someone who you could talk to and feel close to & -0.01 & 0.06 & 0.09 & 0.25 & 0.13 \\
\hline \multirow[t]{2}{*}{17} & Loved one should have taken better care of her or himself & 0.29 & -0.04 & -0.04 & 0.16 & 0.04 \\
\hline & Percent of variance explained by the factor & 32.2 & 11.4 & 8.7 & 7.0 & 5.6 \\
\hline
\end{tabular}

Note. $N=394$. The factors are labeled as following:

1. Protesting the Death

2. Negative Thoughts About the World

3. Needing the Person

4. Less Grief is Wrong

5. Grieving Too Much. 
Table 4.Cronbach's Alpha Coefficients and Correlations Matrix ofthe TBQ Factors.

Croncbach's

Correlations

Alpha

\begin{tabular}{l} 
Factor \\
\hline 1.000
\end{tabular}

Factor 1

0.77

Factor 2

Factor 3

Factor 4

Factor 5

$\begin{array}{llll}\text { Factor } 2 & 0.59 & 0.089 & 1.000\end{array}$

Factor 3

0.79

0.116

0.292

1.000

Factor 4

0.62

0.089

0.310

0.517

1.000

Factor 5

$0.68 \quad 0.041$

0.162

0.346

0.313

1.000

Note.N=394. The factors are labeled as following:

1. Protesting the Death

2. Negative Thoughts About the World

3. Needing the Person

4. Less Grief is Wrong

5. Grieving Too Much. 
Table 5.Correlations of TBQ with Other Instruments.

Pearson

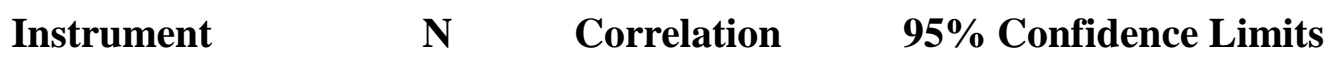

Coefficient

\begin{tabular}{lcccc}
\hline ICG & 394 & .55 & .48 & .61 \\
SCI-CG & 306 & .42 & .32 & .50 \\
GRAQ & 394 & .28 & .18 & .37 \\
QIDS-SR & 385 & .35 & .26 & .43 \\
WSAS & 394 & .39 & .31 & .47 \\
SIGH-A & 394 & .24 & .15 & .33 \\
ISEL subscales: & & & & \\
Tangible Support & 393 & -.14 & -.23 & -.04 \\
Belonging Support & 393 & -.25 & -.34 & -.15 \\
Appraisal Support & 393 & -.19 & -.29 & -.10 \\
Self Esteem Support & 393 & -.31 & -.40 & -.22 \\
\hline
\end{tabular}

Note. All correlations were significant withp $<.001$.

The instruments are as following: ICG - Inventory for Complicated Grief; SCI-CG - Structured Clinical Interview for Complicated Grief; GRAQ - Grief-Related Avoidance Questionnaire; QIDS-SR - Quick Inventory of Depressive Symptomatology -Self-Report; WSAS - Work and Social Adjustment Scale; SIGH-A - Structured Interview Guide for Hamilton-Anxiety; ISEL - Interpersonal Support Evaluation List. 
TABLE 6. Means and Standard Deviations for TBQ Using Dichotomized Scoring for Pre- and Post-

Treatment by Factor for Treatment Responders ( $\mathrm{N}=\mathbf{2 0 6})$ and Non-Responders $(\mathrm{N}=68)$.

\begin{tabular}{|c|c|c|c|c|c|c|c|c|c|c|}
\hline & & Respond & & & & Non-Resp & ders & & & \\
\hline $\begin{array}{c}\text { TBQ } \\
\text { Fac- }\end{array}$ & $\begin{array}{c}\text { Pre- } \\
\text { Treatment } \\
\text { M (SD) }\end{array}$ & $\begin{array}{c}\text { Post- } \\
\text { Treatment } \\
\text { M (SD) }\end{array}$ & $\begin{array}{l}\text { Change } \\
\text { Pre-Post } \\
\text { M (SD) }\end{array}$ & $\begin{array}{c}\text { Effect } \\
\text { Size }\end{array}$ & $\begin{array}{c}\text { Pre- } \\
\text { Treatment } \\
\text { M (SD) }\end{array}$ & $\begin{array}{c}\text { Post- } \\
\text { Treatment } \\
\text { M (SD) }\end{array}$ & $\begin{array}{l}\text { Change } \\
\text { Pre-Post } \\
\text { M (SD) }\end{array}$ & $\begin{array}{c}\text { Effect } \\
\text { Size }\end{array}$ & $t(d f)$ & $\mathbf{p}$ \\
\hline tors & & & & & & & & & & \\
\hline 1. & $\begin{array}{c}3.27 \\
(1.66)\end{array}$ & $\begin{array}{c}1.31 \\
(1.67)\end{array}$ & $\begin{array}{c}1.95 \\
(1.88)\end{array}$ & 1.04 & $\begin{array}{r}3.65 \\
(1.49)\end{array}$ & $\begin{array}{c}3.24 \\
(1.80)\end{array}$ & $\begin{array}{c}0.43 \\
(1.35)\end{array}$ & 0.32 & $\begin{array}{c}-7.23 \\
(158.8)\end{array}$ & $<.0001$ \\
\hline 2. & $\begin{array}{c}1.42 \\
(1.00)\end{array}$ & $\begin{array}{c}0.47 \\
(0.81)\end{array}$ & $\begin{array}{c}0.92 \\
(1.07)\end{array}$ & 0.87 & $\begin{array}{c}1.55 \\
(1.12)\end{array}$ & $\begin{array}{c}1.24 \\
(1.15)\end{array}$ & $\begin{array}{c}0.26 \\
(1.27)\end{array}$ & 0.21 & $\begin{array}{c}-3.86 \\
(100.3)\end{array}$ & 0.0002 \\
\hline 3. & $\begin{array}{r}2.19 \\
(1.91)\end{array}$ & $\begin{array}{c}0.35 \\
(0.95)\end{array}$ & $\begin{array}{c}1.83 \\
(1.81)\end{array}$ & 1.02 & $\begin{array}{r}3.40 \\
(1.99)\end{array}$ & $\begin{array}{r}2.85 \\
(2.13)\end{array}$ & $\begin{array}{c}0.65 \\
(1.57)\end{array}$ & 0.41 & $\begin{array}{l}-4.85 \\
(272)\end{array}$ & $<.0001$ \\
\hline 4. & $\begin{array}{c}1.49 \\
(1.38)\end{array}$ & $\begin{array}{c}0.25 \\
(0.64)\end{array}$ & $\begin{array}{c}1.21 \\
(1.39)\end{array}$ & 0.87 & $\begin{array}{c}1.88 \\
(1.40)\end{array}$ & $\begin{array}{c}1.35 \\
(1.29)\end{array}$ & $\begin{array}{c}0.54 \\
(1.08)\end{array}$ & 0.50 & $\begin{array}{c}-4.07 \\
(145.3)\end{array}$ & $<.0001$ \\
\hline 5. & $\begin{array}{c}1.81 \\
(1.39)\end{array}$ & $\begin{array}{c}0.20 \\
(0.65)\end{array}$ & $\begin{array}{c}1.59 \\
(1.44)\end{array}$ & 1.10 & $\begin{array}{c}1.61 \\
(1.40)\end{array}$ & $\begin{array}{c}1.26 \\
(1.39)\end{array}$ & $\begin{array}{c}0.32 \\
(1.11)\end{array}$ & 0.29 & $\begin{array}{c}-7.52 \\
(146.7)\end{array}$ & $<.0001$ \\
\hline $\begin{array}{l}\text { Total } \\
\text { Score }\end{array}$ & $\begin{array}{l}11.04 \\
(5.20)\end{array}$ & $\begin{array}{c}3.00 \\
(3.68)\end{array}$ & $\begin{array}{c}7.96 \\
(5.47)\end{array}$ & 1.45 & $\begin{array}{l}13.03 \\
(5.01)\end{array}$ & $\begin{array}{l}10.85 \\
(5.81)\end{array}$ & $\begin{array}{r}2.22 \\
(4.23)\end{array}$ & 0.53 & $\begin{array}{c}-8.97 \\
(147.2)\end{array}$ & $<.0001$ \\
\hline
\end{tabular}

Notes.The t-test is comparing whether the change in responders was significantly different from the change in non-responders. The effect size reported here is the mean difference of pre- and post-treatment score divided by the standard deviation of the difference.

The factors areas following:

1. Protesting the Death (5 items)

2. Negative Thoughts About the World (3 items)

3. Needing the Person (6 items)

4. Less Grief is Wrong (5 items)

5. Grieving Too Much (4 items). 